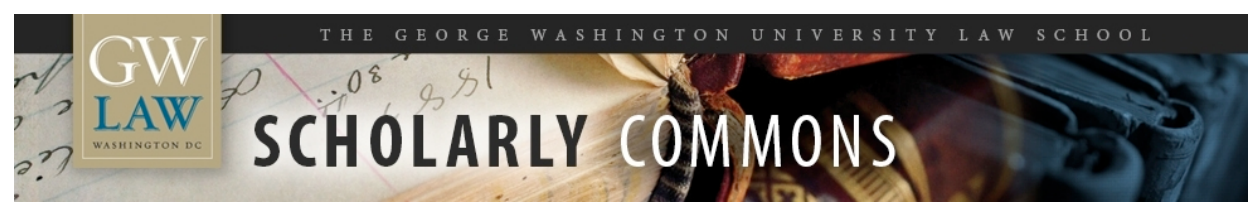

\title{
Puzzling Observations in Chinese Law: When Is a Riddle Just a Mistake?
}

Donald C. Clarke

George Washington University Law School, dclarke@law.gwu.edu

Follow this and additional works at: https://scholarship.law.gwu.edu/faculty_publications

Part of the Law Commons

\section{Recommended Citation}

This Article is brought to you for free and open access by the Faculty Scholarship at Scholarly Commons. It has been accepted for inclusion in GW Law Faculty Publications \& Other Works by an authorized administrator of Scholarly Commons. For more information, please contact spagel@law.gwu.edu. 


\section{Understanding China's Legal System}

Essays in Honor of Jerome A. Cohen

E D I T E D B Y

C. Stephen Hsu

\section{ก}

New York University Press NEW YORK AND LONDON 
NEW YORK UNIVERSITY PRESS

New York and London

C 2003 by New York University All rights reserved

Library of Congress Cataloging-in-Publication Data

Understanding China's legal system :

essays in honor of Jerome A. Cohen /

edited by $\mathrm{C}$. Stephen Hsu.

p. $\mathrm{cm}$.

Includes bibliographical references.

ISBN 0-8147-4254-8 (cloth : alk. paper) -

ISBN 0-8147-4255-6 (paper : alk, paper)

1. Law-China. 2. Law-China-History.

I. Cohen, Jerome Alan. II. Hsu, C. Stephen.

KNQ74 .U54 2003

$349.51-\mathrm{dc} 21$

2002014117

New York University Press books are printed on acid-free paper, and their binding materials are chosen for strength and durability.

Manufactured in the United States of America 10987654321

\section{Contents}

Introduction

C. Stephen Hsu

1 Trying to Understand the Current Chinese Legal System William C. Jones

2 Exporting "the Pursuit of Happiness" William P. Alford

3 Puzzling Observations in Chinese Law: When Is a Riddle Just a Mistake? Donald C. Clarke

4 Grave Matters: Warring States Law and Philosophy Susan Roosevelt Weld

5 The Role of Case Precedent in the Qing Judicial Process as Reflected in Appellate Rulings R. Randle Edwards

6 The Comparative Law School of China Alison W. Conner

7 Law in China's Economic Development: An Essay from Afar Natalie G. Lichtenstein

8 A Legal Perspective on the Development of Electoral Democracy in China:

The Case of Village Elections Jamie P. Horsley 


\title{
Puzzling Observations in Chinese Law When Is a Riddle Just a Mistake?
}

\author{
Donald C. Clarke
}

\section{The Problem of Perplexity}

For a Western-trained lawyer encountering Chinese law for the first time, a reaction other than perplexity is a bad sign-it means that one has not really grasped the depth of the problem of understanding. The evidence that something very different is going on seems clear enough: contract laws are full of mandatory provisions, while tax laws seem to be largely negotiable; judges until recently wore military-style uniforms in court; ${ }^{1}$ and the constitution does not in fact constitute. ${ }^{2}$

There are several ways of dealing with the perplexing features of the Chinese legal system. One way can be called the "naive ignorance" approach. Under this approach, one simply ignores puzzling phenomena and writes about the Chinese legal system ${ }^{3}$ as if it were just like an ideal (not an actual) Western legal system. Thus, an analysis of criminal law or criminal procedure law in China consists of reading and discussing China's relevant legal texts without any consideration for what actually happens. One describes the civil procedure law of China using this approach as one might describe the civil procedure law of, say, France, although a basic-level court judge in China, even if attempting to administer that law in good faith, may well be a retired military officer with no post-secondary education at all, let alone a degree in law.

Because few people would admit to using such an approach, let alone defend it, it is not necessary to spend a great deal of time pointing out its obvious inadequacies. Fortunately, this type of approach is relatively rare (although by no means unknown') in the English-language (and largely 
American) sources. The reason for this is that there is a kind of legal-realist tradition in English-language studies of Chinese law fostered, ironically enough, by the Chinese government and its secretive attitude to the Chinese legal system. In the 1960s, when the first generation of American scholars of Chinese law looked for information on the Chinese legal system, the best way to get it turned out to be through interviewing Chinese émigrés in Hong Kong. ${ }^{4}$ Had the Chinese government made available collections of appellate opinions, quite possibly these scholars would have been happy to forgo the exhausting task of conducting interviews in favor of doing what they had been trained in law school to do: analyze texts. But the result would have been much worse in terms of understanding how the Chinese legal system actually operates. ${ }^{5}$ Instead, the founders of Chinese legal studies in the United States were forced to avail themselves of any source they could get their hands on that seemed remotely relevant, and to piece together what they could of a picture of the Chinese legal system that very obviously was not like their own.

But precisely because a sophisticated approach with at least a modest degree of sensitivity to the new and the unexpected will discover in the Chinese legal system a wealth of such phenomena, it must address the issue of how to interpret them. Indeed, it must address the issue of how to interpret them before they are discovered, because that methodological decision will tend to determine what counts as new and unexpected and therefore what gets discovered. It will also determine which of these discoveries get explained as a normal feature of the system, and which get explained as an error or aberration.

In short, the understanding of the Chinese legal system that results from any study will depend crucially on the selection of a model or paradigm or ideal type-by which terms I intend here essentially the same thing - with which to define what counts as an observation and against which to measure and assess the observations, either descriptively or normatively. This is not to say that the selection of a model will make the difference between understanding and not understanding. It will, however, make a difference between understanding in one way and understanding in another way. Whether one of those ways is better than another depends on how still more methodological issues are settled: the purpose that is to be served by the understanding that is sought, and whether that purpose is itself a valuable one.

What I hope will not be controversial is that we cannot avoid the use of models that necessarily abstract from reality. As Louis Wolcher has written,
It is impossible for a scholar to express any conclusions, causal or otherwise, about reality except by means of abstractions which are, by their very nature, distortions of that which simply "is." ... That which is does not dictate the properties of the discourse by which its intelligibility to humans is rendered, and thus knowledge claims can be properly viewed as simply forms of discourse. ${ }^{6}$

Thus, there can be no question of models that are right or wrong in some absolute sense, just as there can be no choice as to whether or not to use models. The real question lies in how to use them.

My purpose in this essay is to explore the ways in which the Chinese legal system can be understood through the use, conscious or not, of different models, and in particular the phenomenon of what appear to be mistakes and aberrations when we apply those models. I will model, if you will, a particular way of modeling the Chinese legal system, and show how this way of modeling produces observations that can be explained only as errors or aberrations. I will then show how other ways of modeling would explain these observations as normal and expected phenomena. Finally, I will discuss the challenge these multiple ways of modeling pose to the analyst. A model that explains an observation as normal is not necessarily superior to a model that can only explain it as an error or an aberration: mistakes and aberrations do happen. Yet surely it is also intellectually satisfying to have a model of a set of phenomena that provides a plausible account of almost all of them.

\section{Modeling the Modeler}

In this section of the essay I propose to model a particular way of modeling the Chinese legal system. I say "model" instead of "describe" because although the model I propose to construct is rooted in methodologies I see employed in the literature on Chinese law, those methodologies are themselves a kind of reality that can be only imperfectly characterized by an abstraction. Thus, although I believe that it is useful to construct and then in part to criticize this model, I do not claim that any particular analysis or scholar adopts the modeled methodology in toto.

Let me call this model the "Ideal Western Legal Order" (hereinafter the "IWLO") model or approach. Under this essentially teleological approach, the Chinese legal system is identified and measured in terms of an ideal 
end state that is assigned to it by the analyst. Just as we understand the changes in an acorn in terms of the oak tree into which we assume it will eventually grow, so the IWLO approach assigns an end state to the Chinese legal system and evaluates it both statically (how far away is it?) and dynamically (in which direction is it going?) with reference to this end state. Not only does the assigned end state determine the evaluation of the observed phenomena of the Chinese legal system, but it also defines which phenomena shall even count as data about the Chinese legal system and are thus worthy of analysis. To return to the biological example, it is because we are interested in the oak tree that we decide to study the acorn and to ignore, say, the peanut. Thus, the IWLO approach not only determines the standards by which we evaluate the system; it also determines to a large degree the results of the apparently objective process of simply describing the system.

The particular end state used in the IWLO approach is, as the label suggests, the analyst's view of what Western legal orders would look like if their perceived imperfections were eliminated. ${ }^{8}$ This end state constitutes the paradigm, in the Kuhnian sense, ${ }^{9}$ that governs the entire enterprise of analyzing the Chinese legal system.

As argued earlier, there is nothing wrong per se with using a paradigm or model in the course of studying the Chinese legal system. A paradigm is indispensable-it tells us what questions to ask, what observations to make, and how to interpret them. Facts do not simply present themselves to us neutrally; there is an infinity of facts and potential observations in the universe, and we need some structure, some set of categories, to help us make sense of them. ${ }^{10}$

I believe that the IWLO approach modeled above is a useful way of understanding some of the conclusions reached in many contemporary analyses of Chinese law. Again, I do not assert that this approach is invariably "wrong" or useless-I have used it myself, ${ }^{11}$ probably more often than I realize. But any use of models, while unavoidable, has limitations, and the use of this particular model has its own particular limitations that deserve some examination. ${ }^{12}$

The theoretical shortcomings can perhaps best be understood by looking at the naive and sophisticated variants of the IWLO approach. At its most naive, the IWLO approach assumes that the reality of, say, American legal institutions is equivalent to the ideal. The analyst-perhaps a member of Congress or a presidential candidate-wishes to state an evaluation of whether China is a better or worse society than the United States, and does so by comparing China's actual institutions to America's ideal institutions. Thus, for example, China's criminal procedure as actually practiced (and as reported by various human rights organizations) is compared with an ideal picture of the American criminal process (and not the picture as reported by various human rights organizations. ${ }^{13}$ ) Needless to say, China is found wanting, and the conclusion naturally follows that China is bad. As the conclusion was embedded in the premises of the inquiry, however, it does not advance our understanding of China very much.

There is, however, a more sophisticated variation of this approach. The sophisticated version is used not with the conscious purpose of condemning the current Chinese government or 3,000 years of Chinese civilization, but rather with the aim of simply understanding China's legal institutions. (Of course, this aim is not in fact simple, because any goal of understanding must be driven by a particular purpose.) But even the sophisticated approach is flawed by a number of components that are taken for granted and not specifically asserted or supported by argument. ${ }^{14}$

The first assumption is that China has legal institutions. In other words, the IWLO approach assumes that we can talk meaningfully about Chinese law and legal institutions; that China has a set of institutions that can meaningfully be grouped together under a single rubric, and that it is meaningful (i.e., it clarifies more than it obscures) to label this rubric "legal" - the same word we use to describe a set of institutions in our own society. Thus, even to embark on the study of something called "Chinese legal institutions" involves an a priori assumption that China has a set of institutions largely similar to the institutions we call "legal" in our society. If the institutions were not largely congruent-if, for example, we were discussing churches or the movie industry - we would not call the institutions "legal" in the first place. ${ }^{15}$ More specifically, the very act of naming certain institutions involves drawing conclusions about them before the investigation has even begun. If we call a certain institution a "court," then we are claiming that this word conveys to the listener a more complete and accurate picture of the institution in question than some other word. We could equally well call the institution a "team," or an "office," or a "bureau"; the decision not to use those words represents an implicit assertion about the nature of the institution in question. The problem is that this assertion precedes, rather than follows, inquiry into the nature of the institution.

The second assumption is that these institutions are "developing." Academic articles adopting this approach are typically entitled "China's Developing Law of Contract" or something similar. By "developing" is meant 
moving from a more primitive and inferior stage to a more sophisticated and better stage along a trajectory of linear progress toward a well-understood end. In other words, the sophisticated IWLO approach understands a particular institution now by seeing it as a nascent version of an institution in the analyst's vision of an ideal Western legal order. We identify its imperfections in this way and we predict its future changes (which we call "development" and not simply "change").

I believe that bringing this assumption of development into the open is useful in understanding the many articles on the Chinese legal system that point out what it lacks. But how does one decide what the Chinese legal system lacks? Since the phenomenon by definition is not there, one cannot find it by observation. We can decide what an institution lacks only by deciding what it should have, and we can do that only by deciding how to characterize the essential nature of the institution. If we see an oak tree without bark, we would characterize it as "lacking" bark. We would not so characterize a concrete (or even a wooden) telephone pole, although it is equally barkless. To return to the Chinese legal system, it is often said that Chinese judges lack judicial independence. The perception of this lack stems from an interpretation of the institution of Chinese courts and judges that sees them as embryonic courts and judges in ideal Western legal order. If we interpreted the institution of Chinese courts and judges in another light-for example, if we saw them as developing into professional basketball teams-we would discern a completely different set of shortcomings, such as height and athletic ability. The fact that the set of Chinese officials known as shenpanyuan (literally, "adjudication officers") generally lack the attributes of professional basketball players is as real a fact about them as the fact that they lack independence. Similarly, it is a fact that, for example, we could identify some other group of government officials-say, traffic policemen-and point out that they lack independence in the performance of their functions. But it is the vision of an ideal Western legal order that tells us that although the lack of independence of policemen doesn't matter, somewhere in the system there should be offcials who have independence in the performance of their functions. We have then happened upon shenpanyuan as the most likely candidates. But when we look at the matter this way, it is clear that any observation we make is going to tell us more about our own concerns- that is, about our vision of what constitutes an ideal legal order-than it will tell us about China. There's no a priori way of knowing that the fact that shenpanyuan lack independence is at all significant in China. Perhaps it is, but surely the point must be specifically argued-and criteria of significance suppliedand not simply taken for granted.

The main problem with the IWLO approach, then, is that it leaves unstated and unjustified its most crucial component: the ideal against which the Chinese legal system is identified and measured. I do not claim that measuring the Chinese legal system against that ideal is never justified; in international human rights debates, for example, it is meaningful to inquire into the extent to which Chinese legal institutions measure up to international standards, and those standards could fairly be characterized as one version of an ideal Western legal order. The results of this inquiry can be used for information, to prescribe legal reforms, or for condemnation. But they do not come close to telling us everything that might (depending on our purposes) be significant and interesting about Chinese legal institutions. Oak wood may be harder than pine wood, but that does not mean it is the purpose of the oak tree to produce hard wood, or that the oak tree is developing in the direction of progressively harder wood. The hardness of its wood is a particular piece of information that is useful in a limited context-for example, if you are making furniture-but it does not tell us everything, or even the most important thing to someone with a different purpose in mind, about the oak tree.

Because the ideal against which the system is measured is left unstated and unjustified, it is difficult to evaluate the conclusions of an analysis using the IWLO approach. If the goal is to understand the degree to which the Chinese legal system fails to provide the rights set forth in the International Covenant on Civil and Political Rights (ICCPR) recently signed (but not yet ratified) by China, then of course it is legitimate and useful to use the ICCPR as the ideal against which to measure China's legal system. ${ }^{16}$ But if the goal is to understand what China's legal institutions might look like ten years from now, then one cannot simply assume that the direction of change is toward the standards of the ICCPR.

In short, while the IWLO approach can be useful for the limited purpose of assessing whether the Chinese legal system meets some explicitly stated and justified standard, it is by no means the only way of understanding the internal structure and interrelationships of Chinese legal institutions. The sophisticated practitioner of the IWLO approach, unlike the practitioner of the "naive ignorance" approach, can see clearly enough that some phenomena don't fit the ideal; but the sophisticated practitioner 
will nevertheless view these phenomena as aberrations, errors, and imperfections that are not central to understanding the system as a whole. In this way, crucial and important phenomena may be overlooked.

\section{Observations of Error and the Use of Alternative Models}

We cannot avoid the use of models because we need some overarching theory to decide what questions to ask and what observations to deem important. But our inquiry is necessarily beset by a dilemma: we cannot even identify a fact without a model that tells us that it is a fact worth identifying, and yet how can we hope to construct an adequate model prior to the observation of any facts?

The first step, if we have not consciously adopted a particular model, is to recognize that we are invariably working with an existing model, and that this model is what tells us that certain observations are puzzling. The second step is to recognize that the model we are starting may well be unsuited to our aim of understanding Chinese law, since we naturally start with a familiar model, and there is every reason to believe that China, with its different history and political institutions, will require an unfamiliar one. The third step is therefore to take the phenomena that our existing model views as errors and aberrations, and to hypothesize that these phenomena may be normal components of the Chinese legal system when viewed using a different model. If we can construct a model of the Chinese legal system that can account for observations we formerly viewed as evidence of aberration and error, then I think we can be confident that we have gained an understanding we did not have before. Among other things, we will be constructing a more internally consistent model of the Chinese legal system that does not require the use of imported and possibly misleading categories.

Finally, however, we must be prepared for observations that remain inconsistent with whatever model we end up with. These inconsistent observations can be explained in one of several ways. First, they may indeed be evidence of error or aberration in the system. No model can perfectly describe reality; aberration is bound to exist. But if the inconsistent observations are evidence only of minor aberration, then it is not necessary to attach a great deal of importance to them.

Second, the observations themselves may be erroneous. An astronomer who records a position for Mars that is far different from where it is sup- posed to be is more likely to recheck his calculations than to assume that modern astrophysics must be completely rethought.

Third, the observations may indeed be evidence that the model incompletely describes the legal system in ways that are important to us. ${ }^{17}$ This is a signal that we need either to revise the model or to abandon it for one that better serves our purposes.

\section{Alternative Models of the Chinese Legal System: Examples}

\section{A. Introduction}

So far I have only discussed the deficiencies of the IWLO approach in the abstract. I now propose to demonstrate in a concrete way the value of using observations explained as error in that approach to apply alternative models to the analysis of the Chinese legal system.

One of the best thought-out alternative models of the Chinese legal system is that presented by Thomas Stephens in his book Order and Discipline in China. ${ }^{18}$ Stephens' central claim is that we should understand the traditional Chinese legal system-although he would not want to use the term "legal" to characterize the "system" in question-through what he calls the "disciplinary model." The disciplinary model is essentially the model of order that prevails in the army, the family, and the nursery school. His claim is that the entire vocabulary of Western jurisprudencecourts, judges, rights, legislatures, etc.-is inapposite to traditional China, and that to use such terms to describe what we see is to miss the point entirely.

Stephens did not fully work out his model, and in any case was not writing about modern China, but I think it is worth thinking about how the disciplinary model might fruitfully be applied. If it is useful to apply the disciplinary model, that means that if we look at Chinese society as a giant army, or schoolroom, or nursery, certain phenomena will make much more sense than if we see it as a society governed, even imperfectly, by the ideal of the IWLO model.

Of course, it is quite possible that a model designed to fit traditional China's society will not work well when applied to modern China. China does change, and Chinese law in particular is now in a state of profound instability, at least in some respects. There is no single "right" model for the Chinese legal system because at this moment there is a struggle taking 
place in China itself over what the dominant model should be both to describe the Chinese legal system and to reform it. Thus, different models may be appropriate for different fields of law, or even for the same field at different times; we can understand certain observations in one way using one model, and in another way using another model, and in this way attain a fuller understanding of why the observations look the way they do.

\section{B. Contract Law}

The first specific example I propose to look at is contract law. If one looks at Chinese contract legislation in the 1980s and 1990s from the standpoint of the IWLO approach, it appears badly drafted. In particular, it is full of statements saying that such-and-such "should in principle" or "should generally" be done. The question that instantly occurs to a Westerntrained lawyer is: what happens if the particular provision does not appear in the contract? What are the consequences? Is the contract invalid? Can one sue on the contract if the other party does not perform?

These questions are all generated by the IWLO approach. In this model of a legal order, parties make contracts and sue on them, and the dispute is resolved by courts with reference to the words in the contract, applicable law, and possibly commercial custom. Thus, we wonder how a court is supposed to interpret "in principle" or "generally." The terms seem too vague, since they contemplate some exceptions to the rule, but not too many, and provide no guidance as to when an exception is justified. In the rule of law paradigm, these are mistakes; this is bad drafting. The proper response is therefore to give legislative drafting seminars to Chinese officials - to train them to move from a more primitive stage of drafting to a more sophisticated stage.

But suppose we apply the disciplinary model to the same phenomenon. In a disciplinary system, nobody supposes that the state should be a neutral and disinterested enabler of transactions between individuals. On the contrary, from the point of view of this model, if individuals are allowed to do whatever they please they will only end up harming themselves and the community. Therefore, the state (which asserts the authority to speak for the community) closely supervises the actions of individuals. In particular, it supervises the actions of individuals that implicate the legal system, because the legal system consists of state institutions and one doesn't want uncontrolled individuals determining the acts of state institutions.
Within a disciplinary system, therefore, it is natural to set up a contract approval system, in which all contracts of importance (i.e., contracts in the course of economic production) need approval by some state organ. The "laws" of contract are not aimed at individual contracting parties; they do not speak to such parties. Instead, they are essentially instructions from the central state to contract approval organs that tell them how to go about their task of approving contracts. Using this model, it is not at all surprising to see such terms as "in general" or "in principle." The important issue is not one of rights or statutory interpretation; the important issue is whether a kind of statistical regularity is achieved. The drafters recognize that not all contracts need the particular provisions in question. They want most contracts to have these provisions, but do not want to tie their own hands. Contract approval authorities are therefore instructed, in effect, to achieve a conformity rate that is relatively high. It is the contract approval authorities that "obey" and "apply" this rule, not contract parties or courts; the issue of whether the rule has been properly applied is one between the approval authorities and their superiors and is not the business of anyone else. The use of terms such as "in principle" or "in general" can thus be understood not as an oversight or an example of bad drafting, but instead as a perfectly understandable and even necessary part of the system.

\section{The Constitution}

Let us now turn to a set of perplexing observations one could make about the Chinese constitution (xianfa). Most obviously, it does not describe or in a realistic sense prescribe how the government of China operates. ${ }^{19}$ It is perhaps the least important document, in terms of binding force, in the entire Chinese legal system-the most important and binding standards are formulated at formally lower levels such as the State Council and local governments. ${ }^{20}$ Little of importance is done or not done simply because it is written in the constitution. The words of the constitution are essentially epiphenomenal: at most, they reflect the alignment of political forces elsewhere in the system, but do not importantly affect them. Despite this lack of legal significance, however, the government keeps changing the constitution, and these changes are viewed as important in the sense that people debate the language and support or oppose making the changes. How do we explain all this? 
Under the IWLO approach, one would reason as follows: A constitution is a document (or a set of unwritten but well- understood rules) that sets forth the operating rules of the government. In China, the xianfa is that document. China is developing a constitutional system. Eventually it will have a system where government operates according to constitutional norms as interpreted authoritatively by courts. These could be ordinary courts (as in the United States) or special constitutional courts as in some European countries. Where the government does not operate according to the rules set forth in the constitution, that is a constitutional violation and the sign of something wrong in the body politic. Thus, the fact that the Chinese government frequently does not operate in accordance with the norms of its own constitution is a failing; it is a sign of serious political sickness; it is quite possibly even morally wrong.

But while it may be satisfying rhetorically, and useful politically, to bemoan the fact that the Chinese government keeps violating its own constitution, I am not sure that it really advances our understanding of the actual role played by this document, the xianfa, in the Chinese polity. To advance our understanding, I propose that we start by forgetting that the Chinese government translates xianfa as "constitution." I contend that if we do not start with any presuppositions as to what this document is, we are unlikely to conclude that it is a constitution in a meaningful sense-in part because it just doesn't do the things that documents labeled constitutions are supposed to do. ${ }^{21}$ Thus, I suggest we understand the document by interpreting the so-called "violations" as normal phenomena, not as errors or aberrations.

Let us start by considering what a constitution means in the IWLO model, in particular as understood in the common law tradition. In the IWLO model, a constitution can be viewed as a kind of contract. It represents a political deal, an accommodation among competing political groups on how the government of the state should be carried forward.

In this view of a constitution, ${ }^{22}$ violations are significant. They represent breaches of the deal, attempts to change the agreed order of things. There needs to be a system for determining when violations have occurred and deciding what to do about them, and that system needs to have its own legitimacy.

Given this understanding of a constitution, does it make sense to suppose that China would have one? I believe not. The current regime in China is not the result of a political deal; it was the result of a one-sided military victory. Thus, I would claim that China's written xianfa is less of a constitution than the famous unwritten constitution of the United Kingdom, which is very much the product of a series of political deals and understandings. If we accept that the xianfa is nothing like a constitution as the rule of law paradigm understands it, then the "violations" are not puzzling or perplexing; they are simply observations without significance. But this answer will not be satisfactory to most people. Therefore, let us look in detail at why violations of the norms apparently set forth in the Chinese document labeled xianfa are not significant observations once we stop insisting that the xianfa must be a constitution. I propose an understanding of the xianfa that accommodates a view of "violations" as normal or even insignificant, instead of a view that sees them as evidence of error and aberration. The test of the understanding I propose, of course, is simply whether it seems more persuasive than any other.

The first part of my account of the xianfa is to note that it does have significance; it simply does not have much legal significance. The "rights" it provides are more akin to the right to the pursuit of happiness proclaimed in the American Declaration of Independence. The xianfa might thus more appropriately be viewed (and translated) as a kind of National Declaration. Each xianfa to date has marked the ascendancy of a particular leading group and policy orientation. ${ }^{23}$ Each has contained a clear indication of the policy directions the government at the time intended to take. Thus, they have been far from insignificant. But they have not been binding law and no Chinese government has ever treated them as such. ${ }^{24}$ On the contrary, changes to the xianfa are often quite explicitly intended to be the final stamp of legitimation on already existing and approved practices. Land leasing, for example, was carried out experimentally (and with central government approval) at the local level before the prohibition on it was removed from the xianfa. ${ }^{25}$

The notion of the constitution as a National Declaration of the victorious political line explains why China keeps running into the problem of social practice outstripping the constitution (a problem that is typically solved, as with land leasing, by simply ignoring the constitution). The reason goes to why the Chinese government has produced a document that it labels a "constitution" in the first place: a constitution, in the modern world, is a legitimator of government. Virtually every self-respecting state must have one, unless it happens to be a very old, established state like the United Kingdom.

In the United States, where constitutionalism borders on religion, a form of government and its policy decisions are legitimated through the 
observance of proper procedures. ${ }^{26}$ In China, however, the government claims legitimacy through correct policies themselves, not through the way they were produced. The government's slogan is, "Only the Communist Party can save China." It is not, "Only following constitutional procedures can save China." The Communist Party does not say that it deserves to be in power because it was elected or because some other procedure was satisfied. ${ }^{27}$ It asserts its right to power through its promotion of correct policies that will make China wealthy and strong.

If correct policies legitimize a government, and the constitution is a sign of legitimacy, then the constitution should embody the correct policies, not merely a set of procedures. To understand the significance (or lack of significance) of constitutional "violations," let us return to the issue of land leasing in Shenzhen. This leasing was carried out while the policy against the leasing of land was still a legitimizing policy. What happened in Shenzhen was allowed as an experiment of strictly local scope. It did not call into question the larger ban, and thus was not politically disruptive. Once the government was satisfied that leasing land would have no delegitimizing consequences, the constitution could be changed to allow it officially. But since the constitutional rule against land leasing was never intended to be an actual binding rule of law, we will not understand what happened in Shenzhen and later in Beijing if we picture land leasing in Shenzhen as a constitutional "violation" similar in consequences and significance to constitutional violations in, say, the United States.

One can use similar reasoning to analyze the fact that the government does not in fact provide all the rights set forth in the constitution. Under the IWLO approach, a right set forth in the constitution that cannot actually be realized is worthless. It might as well not be there. For the government not to provide such rights is a failure and an error.

But suppose we stop insisting that the xianfa is actually a constitution? Suppose we see it as a kind of National Declaration similar to the American Declaration of Independence- the fact that an American court will not recognize a legal right to "the pursuit of happiness" does not mean that the Declaration of Independence is an insignificant or worthless document. It can be viewed as a declaration of broad policy objectives, or even as a political campaign platform with promises that nobody really expects will be kept. ${ }^{28}$

Looking at the Chinese constitution through different lenses is particularly interesting because in fact no single paradigm is adequate. China is not static, and there is considerable contestation over which model should apply. As someone attempting merely to describe and not to prescribe, I can of course conclude after study that the document labeled xianfa is simply a general statement of policy and should not be taken seriously as a legal document. But plenty of Chinese inside and outside the community of legal specialists are not content with a model that denies legal significance to this document. They want it to have legal significance and are working to ensure that it does. ${ }^{29}$

Ever since the fall of the Qing dynasty and the end of imperial China in 1911, Chinese governments have viewed a Western-style constitution proclaiming popular sovereignty as a necessary hallmark of legitimacy, something that would never have occurred to a Chinese government before contact with the West. In proclaiming the xianfa to be that constitution, a government in effect legitimizes the treatment of the xianfa as a Westernstyle constitution. Although the government is not in fact bound by the xianfa, it cannot admit it. This changes completely the rhetoric of argumentation and justification. A claim by an American citizen that the government had not protected the right to pursue happiness set forth in the Declaration of Independence would be dismissed by an American court; the Declaration of Independence neither is nor is supposed to be a source of law binding on the U.S. government. A claim by a Chinese citizen that the 1989 declaration of martial law in Beijing was invalid because not made according to the procedures outlined in the xianfa would similarly get nowhere, but the grounds of argument are subtly different because the xianfa is, by the government's own admission, supposed to bind it. The government is obliged to respond that the procedures of the xianfa were followed.

The practical importance of a change in rhetorical style should not be overestimated. There is no neutral judge to impose sanctions on the side that loses the argument. But if the government must always claim to be following the procedures of the xianfa, this claim is much easier to make if it actually does follow those procedures. There is thus a constant pressure, imposed by the government's own decision to proclaim the xianfa a "constitution," to act according to its provisions. The revisions leading to the 1982 xianfa, in fact, show evidence of this pressure. Although the government had never in practice allowed strikes, the right to strike was put in both the 1975 and the 1978 constitutions as something appropriate to a workers' state. By 1982, the government had not changed its mind about the right to strike, but it had changed its mind about how far the xianfa should reflect reality: the provision was (along with some others) removed. 
This contestation over the right model can be found in the recent debate over the idea of "benign violations" (liangxing weixian) of the constitution. According to this school of thought, given the persistent and inevitable tensions between the rules of the constitution and the great changes taking place in China, certain constitutional violations should be countenanced where certain conditions are present: it promotes the development of the productive forces, or it is in the basic interests of the state and the people. ${ }^{30}$

Needless to say, there is much to criticize in this theory. First, the proponents are not clear as to who should decide whether these factors are present. Second, it is hard to see why the logical end of the theory is not simply the reduction of the entire constitution to a sentence stating two broad policy goals (promote the development of productive forces and serve the basic interests of the state and the people), with everything else handled by statute. Third, it vitiates the idea of the constitution as a legal document and replaces legal criteria with what are essentially political and economic criteria. There is no place for special legal expertise in judging what will promote the development of productive forces or serve the basic interests of the state and the people.

But the criticisms of this theory made in China are interesting for other reasons. One critic, Xi Zhong, acknowledges that the theory of benign violations attacks a genuine problem: the tension between constitutional rules and social development. In such a case, he states, either social development must be blocked or constitutional rules must be ignored. He goes on to say that in China, it is the latter choice that is always made, and he calls this an "abnormal phenomenon" (bu zhengchang de xianxiang). ${ }^{31}$

Let us think for a moment about this claim. The historical reality is that Chinese governments, including the government of the People's Republic, have always ignored inconvenient provisions of the constitution. ${ }^{32}$ From where comes the extraordinary claim that this is abnormal? If a Western scholar made the same claim, he or she would be accused in some quarters of the worst kind of ethnocentrism. ${ }^{33}$ What we see here, however, is an internal criticism from someone who works within the Chinese legal system. $\mathrm{Xi}$ and others are not outside observers of the Chinese legal system content simply to describe it; the point, as Marx said, is to change it. Interestingly, however, they are not claiming a desire to change the fundamental principles of the Chinese legal system. They are saying instead that the principles they support already exist within the system. Their claim is that the xianfa is a constitution, and that a constitution by nature has certain characteristics; they insist therefore that the xianfa and its associated institutions should exhibit these characteristics.

\section{Administrative Law}

Looked at using the IWLO approach, China's administrative law is indeed perplexing. There just doesn't seem to be very much of it. There are few effective laws or other institutions governing the competence of various bodies to make regulations or governing the exercise of discretion by administrative bodies.

Take the question of legislative competence. It has been frequently observed that different governmental bodies in China issue a bewildering variety of documents containing rules that are apparently intended to be followed. ${ }^{34}$ The purported subject of these rules naturally wants to know whether obedience is compulsory and what to do in case rules issued by different bodies conflict. If we are applying the IWLO model, we will naturally start asking questions about legislative competence. Did the governmental body in question have lawful authority to issue the regulation in question? Using the familiar tools of analysis such as delegation, ultra vires, and legislative intent, it is very difficult to come up with an answer, because these simply are not concepts that the Chinese legal system deals with very much.

Even if we could come up with some kind of answer, the answer would not be significant within the Chinese legal system, because the issue of whether or not you need to obey will not be settled by a court applying these tools of analysis. Thus, the IWLO approach directs our inquiry to a set of concepts that aren't important and guarantees an irrelevant result. To be sure, we can conclude that the Chinese legal system lacks a developed administrative law, but this doesn't advance our knowledge of what it has, and implies that somehow it ought to have a developed administrative law.

The IWLO approach insists that we ask questions to which there is no good answer, and there is no good answer because they simply are not important questions within China. Thus, the answers seem inadequate and confusing, and we therefore label the Chinese legal system inadequate and confusing. With a different model, however, we might be inspired to ask a different set of questions to which clear answers were possible. Suppose we say that the relevant question is really which governmental body has the actual power to enforce the piece of rule-making in question? This is a 
different question that calls for a different type of analysis. Yet one can imagine that it would be quite possible to come up with a realistic answer that had the additional virtue of being useful to someone attempting to accomplish something in the Chinese legal system. By abandoning the IWLO approach, we might be able to replace confusing and useless answers with straightforward and useful ones.

Another example can be found in the notion of control over administrative discretion. It is often remarked that China "lacks" such controls. This is because one can observe that the National People's Congress [NPC] (for example) promulgates an item of legislation; the legislation states that a permit is required to do such-and-such; and it also says that a particular bureaucracy shall decide within $X$ number of days whether or not to issue the permit. But the law typically lays down no criteria for the bureaucracy to use in deciding whether or not to issue the permit-certainly no criteria that might be used as the basis for a lawsuit challenging the bureaucracy's refusal to issue the permit. There is no case such as J.W. Hampton, Jr. \& Co. v. United States ${ }^{35}$ analyzing the question of administrative discretion, even if deciding in the bureaucracy's favor. Therefore, we conclude that such controls over discretion are "lacking" because we think of them as something that should be there. In the IWLO model, the Chinese bureaucracy is like the bureaucracy in a Western European country, and the NPC is like a parliament or the United States Congress. The IWLO model sees Chinese administrative law even though it doesn't really exist in the familiar sense; undeterred, the model thinks of it as simply not existing yet, but as embryonic and in need of nourishment and encouragement. In other words, the basic framework is all there; China simply needs to supplement what is currently lacking.

Again, I would like to see how we can understand China's lack of a developed system of administrative law by abandoning the IWLO approach and instead assuming that what we observe is part of the normal and regular functioning of a system. We can start by taking account of the fundamental political differences between China and a country like the United States with a developed system of administrative law. United States federal administrative law, for example, would not exist without the presence of two different types of institutions: Congress and federal agencies. Many of the questions of administrative law that are interesting for us have to do with the relationship between those two institutions. In particular, we like to ask:
- How much power and discretion can Congress delegate?

- What standards and procedures should guide the exercise of administrative discretion?

- How much deference should courts give to the exercise of administrative discretion?

These legal questions are all important for political reasons: Congress is politically powerful, wants to get things accomplished, and must rely on executive agencies to do it in many cases. Since the whole reason for consigning a task to an administrative agency is that Congress cannot directly implement laws itself, and in many cases does not have the time or expertise to engage in detailed rule-making, administrative agencies must be given a certain amount of discretion. But that discretion may be exercised only in the service of a properly granted mandate from Congress, and therefore some types of controls are viewed as necessary. ${ }^{36}$

In the United States, there is a further requirement that all exercises of government power at the federal level have a specific legal basis; there must be a basis in the Constitution or an authorizing statute, and the statute must be constitutional. Furthermore, it is a court that will decide whether the action is in accordance with a statute or the Constitution.

China, of course, functions politically in a completely different manner. Why would one expect to find in China a system of administrative law that poses and answers the questions important in American administrative law, when the political basis for those questions in absent?

American administrative law is concerned with delegations of power from a legislature: a superior delegates to an inferior. But in China, the "legislature" (the National People's Congress) is not in fact superior to the "executive" or the "administration" (the State Council and its organs). Political power does not come from the NPC. On the contrary, the NPC owes its existence to the "executive," which created it and arguably could abolish it tomorrow without changing anything essential about China.

The real locus of central political power in China-the real government, as it were-lies, of course, in the leadership of the Communist Party, which exercises power largely through the State Council. This government has inherent authority to make rules about anything. For a number of reasons, it now chooses to make certain rules through the vehicle of the National People's Congress. But the issue of which rules are made through the NPC, which through its Standing Committee, and which 
through the State Council is not a legal question; it is largely a political decision.

Thus, it is not a sign of immaturity or inadequacy of the system that China has no effective rules governing lawmaking competence or administrative discretion. In countries where Parliament is supreme, such as the United Kingdom, one does not have rules governing the "exercise of discretion" by Parliament in its activities. The whole idea simply does not make sense. For the same reason, administrative law as understood using the IWLO model looks chaotic and undeveloped because the model we are using does not fit the political facts of life in China. If we want to look at rules governing the exercise of discretion, we should look at how superior organs (for example, the State Council) control their inferior organs (for example, ministries). This, however, is essentially a question of bureaucratic discipline in China and not part of public law.

As we saw with the constitution, however, the story does not simply end with the discovery of a better-fitting model. There are a number of actors in China that are not satisfied with a descriptively more accurate model. They want the model contained in the IWLO approach, and they want to change the way China operates until that model is in fact descriptively quite accurate. They believe that administrative agencies should be subject to NPC legislation, and that China would be a better place were this so. Nevertheless, it is crucial to recognize that this is not a description of China; it is an argument about where China should go that is not now backed by political reality.

\section{Conclusion: Evaluation versus Description}

While evaluating the Chinese legal system and describing it share many common elements and are in some sense inseparable, ${ }^{37}$ they can be usefully distinguished. Frankly, the former is the easier task. You pick some values and see whether they are realized in the Chinese legal system. This can be a legitimate exercise, and can yield information about the Chinese legal system that is useful for some purposes. Thus, an evaluation is always to some extent a description. The problem with an evaluation as a description is that it is an incomplete and possibly misleading description. If all we do is evaluate the Chinese legal system, especially from the standpoint of the IWLO model, then all we can say about differences we find is a series of statements about elements that the ideal contains and that the
Chinese legal system lacks, or elements that the ideal rejects that the Chinese legal system has. All we can say about the system's future is to express the hope that it will become more like the ideal Western legal order. This kind of analysis is in principle unable, except by sheer luck, to grasp important internal relationships within the Chinese legal system, because it is uninterested in them.

Simply describing the Chinese legal system in a way that makes sense of the observations is much, much harder than evaluating it, because there is no ready-made model-one's own value system-to use. One must imagine several models and try them all out to see what kind of understanding they yield. Instead of understanding the Chinese legal system by asking, for example, how far it maximizes the value of individual autonomy, one seeks to understand it by finding out what values it does maximize. Obviously, one can then pass judgment on that value orientation, but one has to find it first.

What makes description doubly difficult is that describing a legal system is not like describing an astronomical system. The observations of the Ptolemaic astronomers were quite accurate; the problem lay in the interpretation they gave to those observations. When Copernicus reinterpreted the observations, the new interpretation-putting the sun at the center of the solar system-proved more convincing than the old, but it did not change the observations.

A legal system, though, is different, because we are interpreting the acts of human beings, who have their own purposes and goals, and who can change their behavior. As I noted when discussing the constitution, many Chinese analysts in a position to affect the shape of Chinese legal institutions are normatively dissatisfied with the model I proposed for understanding it. Whether or not they agree that that is how things are, they certainly do not believe that that is how things should be. They want a different model to apply, and that model, for many, is that of the constitution in the ideal Western legal order. They want violations of the constitution to be viewed by actors in the system as errors and aberrations that must be corrected. They are not only participating in a debate over how to interpret the observations-a debate in which description and evaluation are usually mixed together-but they are also creating the observations.

Indeed, even Western observers are, in an important sense, creating the observations. Like it or not, the Chinese state exists in a world dominated by Western models of international and domestic legal order. Indeed, when the Chinese government argues that it is inappropriate to apply 
Western standards of legal order to the Chinese legal system, or strenuously asserts that the Chinese legal system in fact meets these standardssometimes in the same document ${ }^{38}$-it is appealing in both cases to Western models of justification. Although I believe that legal and other reforms in China must in the end be internally driven and will not occur through the imposition of, say, trade sanctions by other countries, this is by no means to say that Western models will play no important role in the direction those reforms take. And it is Western observers who are continually creating and recreating those models, and measuring China against them. Moreover, there is increasing interaction between Western observers and Chinese participants.

Consequently, even a model that appears at one particular moment to be the most useful in terms of achieving the purpose for which it was intended is unstable and incomplete if it is unsatisfactory--whether for moral or practical reasons-to powerful observers and especially to participants. They will be looking for ways to subvert it from within. Thus, if we note incompatible observations, these may not simply be errors; they may be signs of an alternative model that co-exists with the dominant model. Consequently, the best attainable understanding of the Chinese legal system will not be simply the best-fitting model plus incompatible observations explained as errors. We must be prepared to apply multiple models and to be alert to the need always to move nimbly among them.

\section{Appendix}

A Digression on Ethnocentrism and the Canadian Giraffe

This essay is an attempt to come to grips with some of the problems of understanding institutions in a society different in many ways from the one with which I am familiar. A necessary corollary of two societies' being different is that each society will have institutions that the other does not. Yet anyone from a Western society who asserts that non-Western Society $X$ does not possess Institution $Y$ is, if Institution $Y$ is generally present in Western societies and considered to be a good thing, vulnerable to the charge of ethnocentrism in one form or another. The general form this charge takes is that the person criticized has adopted a definition of a concept that is too narrow; were we to adopt a broader definition and more inclusive definition-which the critic asserts we should do-we would see that Society $X$ really does have Institution $Y$, albeit in a somewhat different form. The critic asserts that we should accept that different form as a local manifestation of Institution $Y$, just as what we call Institution $Y$ in Western society is really just a local manifestation of a broader concept. For convenience, I will refer to criticism of this type as "You're Too Narrow" (YTN) criticism.

There is nothing in principle wrong with this kind of criticism; it may at times be justified. At other times, however, the criticism is marred by two typical flaws. First, the YTN critic often interprets an assertion that Society $X$ does not have Institution $Y$ as an assertion that Society $X$ is bad, and seeks to defend Society $X$. He does so, however, not by refuting the proposition (which may or may not have been specifically asserted) that failure to have Institution $Y$ is bad, but by insisting that Institution $Y$ really is present if only we were imaginative enough to see it. In other words, the critic misunderstands what makes ethnocentrism a moral and methodological error. It would be ethnocentric for a Kenyan, for example, to assert that only countries to which giraffes were native were good countries; it would not be ethnocentric to assert that Canada had no giraffes. One cannot convincingly refute the claims of our ethnocentric Kenyan by insisting that caribou are simply Canada's version of a giraffe and that the Kenyan should not use such a culture-bound definition of what constitutes a "real" giraffe.

The anthropologist Paul Bohannan points out an example of this type of YTN approach in the work of fellow anthropologist Max Gluckman, who stated in his book The Judicial Process among the Barotse of Northern Rhodesia that "it is unfortunately still necessary to demonstrate that Africans ... use processes of inductive and deductive reasoning which are in essence similar to those of the West, even if the premises be different." ${ }^{39}$ Comments Bohannan: "He wants, in short, not merely to study a culture and society, but also to prove that Africans are as good as anybody else."40

The project of demonstrating Society $X$ to be as good as Society $Z$, particularly in the face of ignorant and genuinely ethnocentric views in Society $Z$ about Society $X$, can be a worthwhile one-but it should not be confused with the project of determining whether Society $X$ has institutions that can meaningfully be called by the same name ${ }^{41}$ as certain institutions in Society $Z$. Unfortunately, the confusion is often increased by the fact that the YTN critic may simply assume that everyone understands the debate to be over whether Society $X$ is good or not, and thus does not make clear that this is the proposition she is attempting to refute. The refutation 
is couched in terms of the seemingly abjective question of whether the institutions in question do or do not exist in Society $X$.

The second typical flaw of the YTN approach is that while criticizing the narrow definition used by the target of criticism, the critic fails to justify or defend her own definition or even to propose and defend a standard by which the merit of a definition should be judged. The point of any definition, however, is that it must be useful for the purpose it is to serve; its usefulness cannot be measured in the absence of an understanding of that purpose. Take the issue of how to define "the rule of law." If the question "Does Country $X$ have the rule of law?" is posed by legislators of Country $Z$ and is really the question "Is Country $X$ a rogue state that should be subject to sanctions by Country $Z$ ?" (perhaps a legitimate question in the right circumstances) in disguise, clearly a narrow definition that includes virtually every specific feature of Country $Z$ s legal system is absurd. If, however, the question "Does Country $X$ have the rule of law?" is being posed by a judge in a court of Country $Z$ with two parties in front of her, and is really the question "Does Country $X$ have a legal system such that the courts of Country $Z$ should automatically enforce its courts' judgments without further inquiry?" (also a legitimate question in the right circumstances) in disguise, it seems equally clear that a more narrow and "ethnocentric" definition is entirely appropriate.

\section{NOTES}

I wish to express my thanks to Paul Gewirtz of Yale Law School, Koguchi Hikota of Waseda University Faculty of Law, and Randall Peerenboom of the University of California at Los Angeles School of Law, whose invitations to speak at their respective institutions were instrumental in prompting and developing the ideas in this essay. I also wish to thank Michael Dowdle, Daniel Foote, Ellen Hertz, Randall Peerenboom, and Louis Wolcher for their generously detailed comments on an earlier draft, and I especially wish to thank Prof. Wolcher for his methodological insights. Needless to say, none of these bears any responsibility for the result.

Given the forum for the publication of this essay, I wish also to take this opportunity to thank Jerome Cohen for awakening my interest in Chinese law when I found his book on the Chinese criminal process in the library of the Canadian Embassy in Beijing over 20 years ago, and for being a constant source of encouragement, advice, and very concrete assistance on many occasions since then. It is a measure of Jerry's impact on the field, and a tribute to it, that there are so many of us who are probably saying more or less the same thing. This essay is dedicated to him.
1. See "Faguan kaiting chuan faguan pao" (Judges Wear Judicial Robes in Court), Zhongguo Fayuan Bao (China Court News), March 8, 2000, p. 1. This article includes pictures of models posing in the new robes.

2. See, e.g., William C. Jones, "The Constitution of the People's Republic of China," Washington University Law Quarterly, vol. 63, no. 4 (1985), p. 710 ("The constitution seems to bear no relation to the actual government of China").

3. Both Stanley Lubman and Perry Keller have questioned whether China's legal institutions and norms exhibit the kind of unity that would justify calling them a "system." See Stanley Lubman, Bird in a Cage: Legal Reform in China after Mao (Stanford: Stanford University Press, 1999), p. 3; Perry Keller, "Sources of Order in Chinese Law," American Journal of Comparative Law, vol. 42, no. 4 (1994), p. 711. This is an interesting issue, but not one I intend to address here. By "Chinese legal system" I mean merely the set of Chinese institutions and norms commonly understood as "legal" by those who study them.

4. See Jerome A. Cohen, "Interviewing Chinese Refugees: Indispensable Aid to Legal Research on China," in Jerome A. Cohen, ed., Contemporary Chinese Law: Research Problems and Perspectives (Cambridge, Mass.: Harvard University Press, 1970), pp. 84-117; Victor H. Li, "The Use of Survey Interviewing in Research on Communist Chinese Law," in id., pp. 118-138.

5. A recent example of the instinctive preference of common law scholars for case reports as the raw material of legal study can be found in the publication by Butterworths Asia of the China Law Reports, a translation of excerpts from Zhongguo Shenpan Anli Yaolan (Anthology of Adjudicated Cases in China) (Beijing: China People's Public Security University Press, 1992). In its design and very title, the China Law Reports appears to be a reporter of judicial opinions of the kind familiar to Western lawyers. Yet judicial opinions are not, in fact, important sources of law in China, and the decisions contained in the China Law Reports are not in any case those that were originally issued by the judges that made them. The texts were heavily edited by the law professors and senior judges that put out the Chinese collection. See Peter Feng, "Review," in Hong Kong Law Journal, vol. 26, pt. 2 (1996), pp. 268-273. For all these reasons, the texts are therefore almost wholly unsuited for the analytic treatment they are likely to receive by readers unaware of these problems.

6. Louis E. Wolcher, "The Many Meanings of 'Wherefore' in Legal History," Washington Law Review, vol. 68, no. 3 (July 1993), p. 579.

7. If the model had an explanation for every phenomenon under study, its explanatory power would be suspect; many people would feel that an explanation that explained everything was too elastic to explain anything.

8. Thus, the use of the IWLO approach would by no means be limited to conservative defenders of the status quo in Western countries. It could be used to analyze China by defenders as well as opponents of the death penalty, the exclusionary rule, or abortion rights. I do not include among its potential users those, 
whether or not citizens of Western countries, whose vision of an ideal legal system is radically different from that currently prevailing in those countries.

9. See Thomas S. Kuhn, The Structure of Scientific Revolutions (3d ed.) (Chicago: University of Chicago Press, 1996).

10. For a discussion of the types of questions and research agenda generated by a paradigm of any kind in the course of comparative legal study, see Mark Van Hoecke and Mark Warrington, "Legal Cultures, Legal Paradigms and Legal Doctrine: Towards a New Model for Comparative Law," International and Comparative Law Quarterly, vol. 47, pt. 3 (July 1998), pp. 514-515.

11. See, e.g., Donald C. Clarke, Wrongs and Rights: A Human Rights Analysis of China's Revised Criminal Code (New York: Lawyers Committee for Human Rights, December 1998).

12. It is probably worth repeating at this point that I am modeling the use of a model. In other words, I believe that while a description of a particular analysis of Chinese law as "using the IWLO model" could never be exhaustively accurate any more than a description of the actual economic system of the United States as "capitalist" could, measuring features of the analysis against an ideal IWLO analysis can be helpful in understanding its limitations.

13. See, for example, the often (unintentionally) hilarious debate between William Schultz, the executive director of Amnesty International in the United States, and Sheriff Joseph Arpaio, head of "the toughest prison system in the country," on the Today show of Oct. 12, 1998 (NBC News Transcripts, Oct. 12, 1998).

14. This is not, of course, necessarily a fatal error-we could not communicate at all if we could not take some things for granted and had to prove the usefulness of each word we used.

15. Thus, for example, to Max Gluckman's statement that "the Lozi judicial process corresponds with, more than it differs from, the judicial process in Western society," fellow anthropologist Paul Bohannan responded, "Of course it does, or Gluckman could not have defined it as judicial." See Paul Bohannan, "Ethnography and Comparison in Legal Anthropology," in Laura Nader (ed.), Law in Culture and Society (Chicago: Aldine Publishing Co., 1969), p. 411.

16. See, for example, Donald C. Clarke, Wrongs and Rights: A Human Rights Analysis of China's Revised Criminal Code (New York: Lawyers Committee for Human Rights, 1998), the central purpose of which is to measure China's current criminal law against international human rights standards.

17. It goes without saying, of course, that the model will be incomplete. The issue is whether the incompleteness matters.

18. Thomas B. Stephens, Order and Discipline in China (Seattle: University of Washington Press, 1992).

19. See Jones, supra note 2.

20. For a more sustained treatment of this general point, see Donald C. Clarke,
"State Council Notice Nullifies Statutory Rights of Creditors," East Asian Executive Reports, vol. 19, no. 4 (April 15, 1997), pp. 9-15.

21. On the issue of who gets to define what a constitution is "supposed to do," see note 22 , infra, and the Appendix to this essay.

22. Obviously this view is not the only possible view. It does have the virtue of making a meaningful comparative constitutionalism possible, because it allows the comparison of rules that perform similar functions, instead of requiring the comparison of any document claimed by a government in its English-language publications to be a "constitution." The latter approach appears to be the one implicitly taken by various "Constitutions of the World" collections.

23. See Jones, supra note 2, pp. 711-713.

24. See the discussion at note 28 infra.

25 . As early as 1986, official sources explicitly praised the "leasing" of rural land by local farmers to more productive outsiders. See Xinhua General Overseas News Service, "Farmers Create New Form in Rural Reform," November 6, 1986 (Item No. 1106037). In 1987, the city of Shenzhen auctioned off the "right to use" plots of land for fifty years. See Xinhua News Agency, "Shenzhen to Reform Land Management System," July 7, 1987, in British Broadcasting Corporation, Summary of World Broadcasts, Part 3: The Far East, July 11, 1987, p. BII/1. And of course, Sino-foreign joint ventures had been operating on what was for all intents and purposes leased land for years by that time. The constitutional amendment permitting leasing was not passed until April 1988.

26. An interesting example of this can be seen in the recent controversy over whether or not President Clinton should have been impeached. The President's supporters argued, and his foes felt compelled to deny, that the impeachment drive was simply an effort to overturn the results of the last election.

27. To be exact, the Communist Party does in fact occasionally make something like a claim of legitimacy through popular choice: the claim that it deserves to be in power because the Chinese people chose it in the civil war against the Kuomintang. This claim is not made frequently, however, and is not relied on any more by the Communist Party as a major source of its legitimacy. The war ended, after all, half a century ago.

28. One might analogize a Chinese citizen attempting to force Chinese courts to recognize constitutional rules to a U.S. citizen attempting to force U.S. courts to recognize rules contained in non-self-executing treaties (such as the World Trade Organization agreements) to which the United States is a party. These rules have no place in the American legal system until Congress makes a specific enactment. Similarly, the right of free speech in the Chinese constitution means nothing as a legal right, even formally, until enacted into statute. It is generally acknowledged that constitutional provisions cannot form the basis of a court judgment, and courts are not supposed to cite it. For a recent article arguing that this principle 
neither is nor should be a valid rule within the Chinese legal system, see Wang Zhenmin, "Woguo xianfa ke fou jinru susong" (Can Our Country's Constitution Be Brought into Litigation?), Fa Shang Yanjiu (Studies in Law and Commerce), No. 5, 1999, pp. 28-36.

29. An interesting parallel can be seen in the constitutional history of post-war Japan. The constitution there can also be seen as the result of a one-sided military victory, although not, it must be added, on the part of the largely conservative political elite into whose hands eventually fell the responsibility for enforcing (or ignoring) its provisions. Nevertheless, the fact that it was taken seriously by some as a constitution essentially within the IWLO model led in fact to its functioning more as such.

30. See, for example, Hao Tiechuan, "Lun liangxing weixian" (On Benign Violations of the Constitution), Faxue Yanjiu (Legal Studies), No. 4, 1996, p. 90.

31. Xi Zhong, "Dui 'liangxing weixian' de fansi" (Some Thoughts about "Benign Violations of the Constitution"), Faxue Pinglun (Legal Studies Review), no. 6, 1998, pp. 26-33.

32. See generally Andrew J. Nathan, "Political Rights in the Chinese Constitutional Tradition," in Chinese Democracy (London: I.B. Tauris \& Co., 1986), pp. 107-132.

33. See Janet E. Ainsworth, "Interpreting Sacred Texts: Preliminary Reflections on Constitutional Discourse in China," Hastings Law Journal, vol. 43, no. 2 (Jan. 1992), pp. 278-280. While Professor Ainsworth criticizes scholars such as Jerome Cohen for their ethnocentric conceptions of what a constitution is and how it should be interpreted, it is not clear why Prof. Ainsworth's conception of a constitution-"a specific type of written text-... a political text which is both foundational and generative of subsequent juridical discourse" (p. 281)-is not open to the same criticism. A culture-free conception of a constitution is as chimerical as a culture-free conception of a haiku. I discuss this point further in the Appendix to this essay, "A Digression on Ethnocentrism and the Canadian Giraffe."

34. The most penetrating analyses of this issue of which I am aware are those of Perry Keller in his "Legislation in the People's Republic of China," University of British Columbia Law Review, vol. 23, no. 3 (1989), pp. 653-688, and "Sources of Order in Chinese Law," American Journal of Comparative Law, vol. 42, no. 4 (1994), pp. 711-759.

35. 276 U.S. 394 (1928). Writing for the Court in Hampton, Chief Justice Taft stated, in language that has since become famous, that Congress was required to do no more than "lay down by legislative act an intelligible principle to which the person or body authorized to [exercise the delegated authority] is directed to conform"-but it did have to do that much. Id., at 409.

36. At times, of course, Congress may quite intentionally grant wide discretion to administrative agencies as a way of avoiding difficult decisions; there are some decisions, however, that it is not constitutionally allowed to duck.
37. This is especially so because we are dealing with a legal system, which is all about norms, and not, say, the solar system.

38. See, for example, Information Office of the State Council of the People's Republic of China, 50 Years of Progress in China's Human Rights (February 17, 2000), which states both that "China cannot copy the mode of human rights development of the developed Western countries, nor can it copy the methods of other developing countries.... China can only start from its own reality and explore a road with its own characteristics" and that "China guarantees, according to law, that citizens enjoy extensive basic freedoms and rights... [such as] freedom of speech, of the press, of assembly, of association, of procession, of demonstration and of religious belief."

39. Max Gluckman, The Judicial Process among the Barotse of Northern Rhodesia (Manchester: Manchester University Press, 1955), p. 271.

40. Bohannan, supra note 15, p. 409.

41. I do not want to be understood as insisting that a word can be used correctly in only one way (my way). A speaker can meaningfully call two institutions by the same name if their similarities, measured by a standard that is meaningful to the speaker, outweigh their differences. To call things by the same name, it seems to me, necessarily involves making an implicit claim of this kind. See note 15 , supra, and accompanying text. 